\title{
A review on the methods to mitigate the challenges in photovoltaic system
}

\author{
Rina Syazwani Zulkafli ${ }^{1}$, Nasrul Amri Mohd Amin ${ }^{1, ~ *}$, Mohd Sani Mohamad Hashim ${ }^{1}$, \\ Mohd Hafif Basha ${ }^{1}$, Mohd Shukry Abdul Majid ${ }^{1}$, Ruslizam Daud ${ }^{1}$, and Izzuddin Zaman ${ }^{2}$ \\ ${ }^{1}$ School of Mechatronic Engineering, Universiti Malaysia Perlis, Pauh Putra Campus, 02600 Arau, \\ Perlis, Malaysia. \\ ${ }^{2}$ Faculty of Mechanical and Manufacturing Engineering, Universiti Tun Hussein Onn Malaysia, Parit \\ Raja, 86400 Batu Pahat, Johor, Malaysia.
}

\begin{abstract}
The quantity of electricity produced from the photovoltaic (PV) system is depends on the PV panel's performance itself. Recently, the challenges in the PV system have been greatly discussed by researchers and environmentalists. The non-uniform PV output power, partial shading conditions and high operating temperature of PV cells are the challenges that always known to reduce the PV system's performance. This paper provides a literature review on the challenges and methods to mitigate the challenges. The future works involving of modelling and computational techniques also has been proposed to overcome the problems, hence, enhancing the PV system's performance.
\end{abstract}

\section{Introduction}

Electricity is acknowledged as one of the main driving forces in most of the countries in the world. The challenge of consistently generating power and meeting the local demands is increased, causing remarkable need for an alternative source.

Due to the exhaustion of fossil fuels, increasing global warming, and growth in energy demands, the concern for renewable energies utilization has become more significant than any other resources [1]. Renewable energy promises a reduction of air pollutions [2] as well as covering the needs for electricity generation. Among the renewable energy resources available today, the solar energy is the most promising backup energy since it gives many benefits over other resources [3-4]. Solar energy generation is forecasted to increase by $28 \%$ by the end of 2016 compared to other renewable energy sources [5]. The projection of the electricity generation from utility-scale plants can be shown in Figure 1. The general increments are due to the inherent characteristics, abundant all over the years and free gas emission resources interest most utility companies [4].

PV panel is a medium used to harvest the solar energy. The biggest advantages of using PV panel are the simple and flexible construction [6] with high overall efficiency [7]. Furthermore, low installation and maintenance cost are the main characteristics that have

\footnotetext{
*Corresponding author: nasrulamri.mohdamin@unimap.edu.my
} 
highlighted the benefits of this technology [6]. Recently, as shown in Figure 2, the number of PV panel installations is increased dramatically due to the low price of PV panels [8].

Nonetheless, apart from the advantages, one of the main characteristics of solar energy is the high variability of their output power [9]. In certain locations, the electricity demand is higher than the available sun irradiation. Thus, it may affect the efficiency and flexibility of the PV panel.

An extensive literature review has been carried out and focused on the PV system challenges and methods to overcome the challenges. The rest of this paper is organized as follows. Section 2 presents an overview of solar energy and PV power conversion. Section 3 briefly describes the main challenges in PV application. Section 4 provides the methods to improve the PV efficiency. A detailed discussion regarding the future methods to optimize the system is given in section 5. Finally, the drawn conclusions from this paper are provided in section 6 .

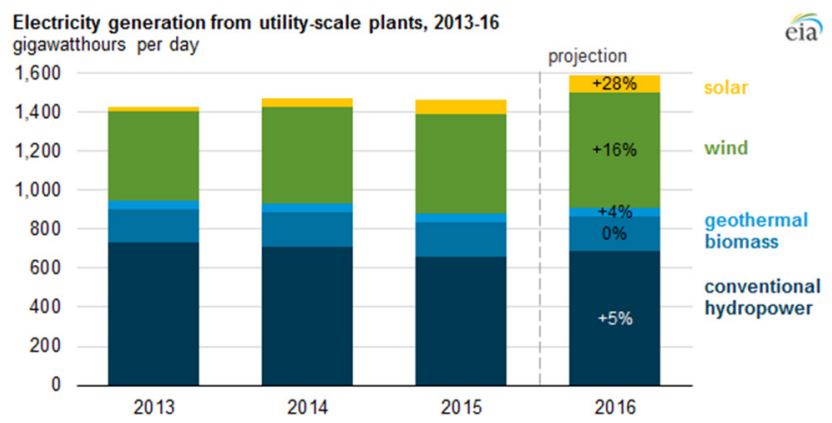

Fig. 1. Increasing projection of solar energy [5].

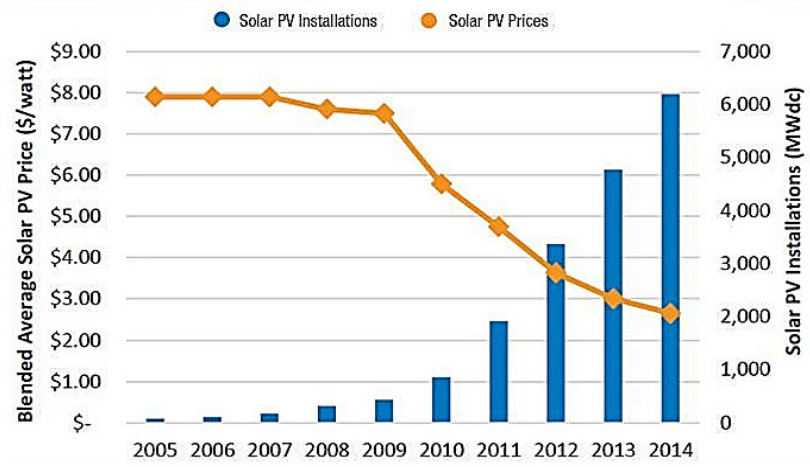

Fig. 2. Solar PV installation vs. solar prices [8].

\section{Photovoltaic Power Conversions}

Theoretically, the solar energy can be harvested in electrical form and thermal form. The sunlight is converted directly via PV panel into electricity. On the other hand, the solar thermal energy concentrates the irradiation from the sun to create heat. The heat will be used to run a heat engine which turns a generator to make electricity.

Solar photovoltaic and solar thermal are capable of supplying a continuous electrical supply. Both of them could cover the worldwide demands for electricity consumption [10]. Nevertheless, solar PV has been found to have a large potential to generate electricity. The penetration of PV technology has fundamentally expanded worldwide in the most recent 
decade [11-12]. The application is ranging from small rooftop or building-incorporated PV frameworks to multi-MW PV. According to Information Handling Services IHS, by the end of 2017, the commercial value of PV technology is expected to rise up to $1.67 \%$ per year [13].

PV cells can generate electricity by directly converting the sunlight absorbed in PV system. Multiple PV cells form a PV module and a series or parallel of PV modules form a PV array system. PV cell is a light absorption component that absorbs the sunlight photon and produces free electron from the PV reaction. The cell is built up with a barrier which helps the electrons to produce voltage [2].

There are two types of solar cell which are crystalline solar cell and thin-film solar cell. The crystalline solar cell is divided into two types which are mono-crystalline solar cell and multi-crystalline solar cell. Meanwhile, the thin-film solar cell is consist of amorphous silicon, cadmium telluride and copper indium gallium de-selenite (CIGS).

PV installation can technically be divided into two configurations which are stand-alone or grid-connected PV system, as shown in Figure 3 and 4 respectively [12]. In a stand-alone PV system, the load is not connected to the utility grid and relies only on a set of batteries that being charged by the PV panel for use at night or during the light intensity of sunlight is limited [14]. Meanwhile, for grid-connected PV system, the power is supplied both from PV panel and the utility grid. There is no storage capacity to store the excess energy generated from the PV panel. Thus, the power from the grid is used for night usage and if the solar intensity is low during the day.

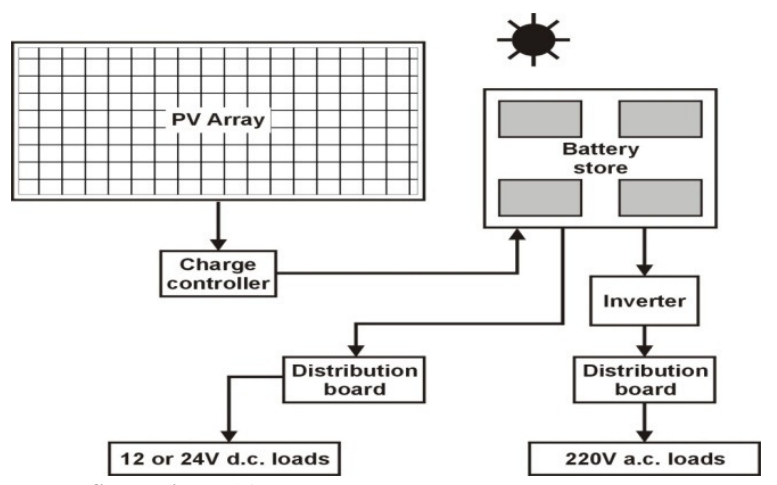

Fig. 3. Stand-alone PV configuration [12].

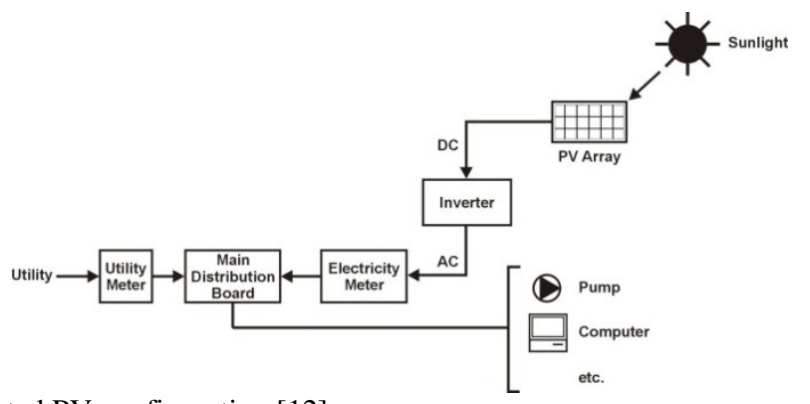

Fig. 4. Grid-connected PV configuration [12]. 


\section{Main Challenges in PV Application}

Though the solar PV system can contribute more to the electricity generation, there are main challenges associated with PV system applications. The challenges include non-uniform PV output power, partial shading condition and high operating temperature of PV cells.

\subsection{Non-uniform PV Output Power}

The main challenge in PV system application is the non-linear output power. Installing PV system in feeder would contribute to problems such as non-linear output power or known as voltage fluctuation in electric power system. As a result, the electricity generated is not constant and unstable [4].

Power fluctuation is a phenomenon where the generated power is unsteady. It occurs when there are obstacle blocks the irradiance from the sun and resulting to the unstable power production. An obstacle such as passing cloud would contribute to the voltage fluctuation [7, 15]. The location and penetration level of the PV system and the topologies of the PV system also affecting the output power generation [9]. In addition, poorly sizing of PV system are one of the causes for voltage fluctuation problem. A PV system with a lower power absorption capacity will reduces the amount of power that can be stored.

\subsection{Partial Shading Conditions}

At times, PV system produces low output power because of the mismatch and a partial shading condition. This is due to the moving clouds, shadows of trees, building and overcast conditions [16-17] causing some parts of the PV array do not receive a uniform sunlight.

To this fact, the partial shading condition (PSC) may exist. PSC will results on multiple local and global peaks which affects the reliability of the power generation. The PV array power curve during PSC is shown as in Figure 5 [16].

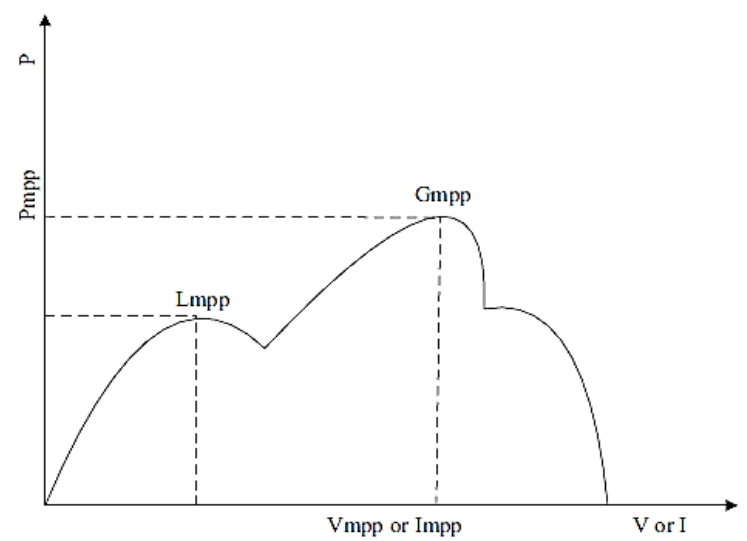

Fig. 5. PV array power curve during partial shading condition [16].

Nonetheless, PSC can be enhanced either through PV panel reconfiguration, framework structures, and converter circuit topologies or optimized MPPT techniques. The improvement of optimized MPPT based method is more appealing because of its implementation simplicity, low cost, and adoption to the existing system promptly. 


\subsection{High Operating Temperature of PV Cells.}

Cooling system of PV panels is a critical issue in the design and operation of the PV system since the overall performance of solar panels is strongly dependent on the effect of PV cells' operating temperature [18]. Current mismatching problem and hot spot may exist due to the high and non-uniform cell temperature, resulting in reduction of PV panel efficiency.

The most affected parameter due to the temperature rise is open-circuit voltage. The high temperature of PV cells may decrease the performance of PV cells. In practice, only 15-20\% of the solar irradiation can be converted into electricity and the rest is being wasted as heat [19]. On top of that, the resistance in circuit will increase, resulting in the low speed of electrons' conversion. The raises of PV cells' temperature can also affecting the properties of solar cell materials.

A uniform cooling is essential to enhance the high performance of PV panel and to ensure a longer PV panels' life at the same time.

\section{Methods to Improve the PV System Efficiency}

\subsection{Energy Storages}

The fluctuation of output power problem can be solved by installing a dump load $[9,20]$. The dump load reduces the power injected into the grid during period of high fluctuations. The dump load consists of a resistance and a controller to control the power flow through the load. It is used as a balancing mechanism. It helps in maintaining system frequency and reduced the voltage variations respectively [21]. However, installing a dump load may increase the system cost, reducing the lifetime system and complicating the operation and maintenance [22].

Other than installing a dump load, a static synchronous compensator (STATCOM) can be used to fix poor power factor and power system which has poor voltage regulation [4]. An integration of PV system with STATCOM were tested to compensate the voltage regulation, harmonic and reactive power [23-25].

Nonetheless, the integrated system gave output of a unity power factor at day time and varying power factor at night. This is opposes the Institute of Electrical and Electronics Engineers (IEEE) 1547 standard as well. The IEEE 1547 only allows a unity power factor output only. On top of that, the device is expensive and less practical for small scale distributed generation system connected to low voltage network [12].

Recently, energy storage system appears to be an effective approach for mitigate the voltage fluctuation issue $[4,15,26]$. The integration of PV system with energy storage system will help to extend the output power of the PV system. Energy storage such as superconducting magnetic energy storage (SMES) [27-29], super capacitor [30-31], battery $[9,32-36]$ is widely used as a backup storage.

An SMES store electric energy in the form of magnetic field developed inside a superconducting coil. A large amount of electrical energy can be drawn from a relatively small magnet. It has some strength to be chosen as energy storage such that it has higher efficiency and has the longest lifetime. On top of that, it has high power density [9]. However, it is expensive, having low energy density and large energy losses compared to the battery. The result was presented as in Figure 6. 


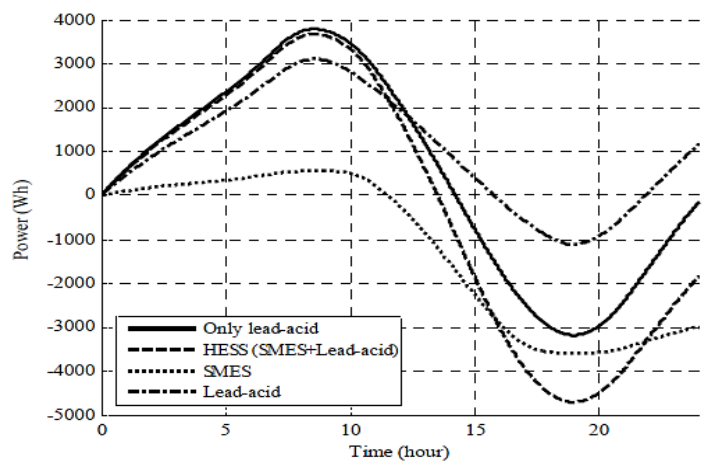

Fig. 6. The energy storages performance [30].

Table 1. Summary of energy storage technologies [37].

\begin{tabular}{|c|c|c|c|c|c|c|c|}
\hline & $\begin{array}{c}\text { Efficiency } \\
(\%)\end{array}$ & $\begin{array}{c}\text { Capacity } \\
(\mathrm{MW})\end{array}$ & $\begin{array}{c}\text { Energy } \\
\text { density } \\
(\mathrm{Wh} / \mathrm{kg})\end{array}$ & $\begin{array}{c}\text { Capital } \\
(\$ / \mathrm{kWh})\end{array}$ & $\begin{array}{c}\text { Lifetime } \\
(\text { years })\end{array}$ & $\begin{array}{c}\text { Self- } \\
\text { discharge } \\
(\text { per day })\end{array}$ & $\begin{array}{c}\text { Charge } \\
\text { time }\end{array}$ \\
\hline SMES & $95-98$ & $0.1-10$ & $0.5-5$ & 10,000 & $20+$ & $10-15 \%$ & $\begin{array}{c}\text { Minutes } \\
\text { to hours }\end{array}$ \\
\hline $\begin{array}{c}\text { Super- } \\
\text { capacitor }\end{array}$ & $90-95$ & 0.3 & $2.5-15$ & 2,000 & $20+$ & $20-40 \%$ & Seconds \\
\hline Battery & & & & & & & \\
\hline Pb-acid & $70-90$ & $0-40$ & $30-50$ & 400 & $5-15$ & $0.1-0.3 \%$ & Hours \\
\hline Na-S & $80-90$ & $0.05-8$ & $150-240$ & 500 & $10-15$ & $\sim 20 \%$ & Hours \\
\hline Ni-Cd & $60-65$ & $0-40$ & $50-75$ & 1,500 & $10-20$ & $0.2-0.6 \%$ & Hours \\
\hline Li-ion & $85-90$ & 0.1 & $75-200$ & 2,500 & $5-15$ & $0.1-0.3 \%$ & Hours \\
\hline
\end{tabular}

Thus, a hybrid energy storage system is proposed, combining the SMES and lead-acid battery to optimize the charging and discharging operations.

A super capacitor is a high-capacitance device that holds hundred times of energy than the conventional capacitor. In the super capacitors, the dielectric is replaced by an electrolyte ionic conductor, and the area separation between the electrodes is much lower than the capacitor. Super capacitor has higher efficiency and longer lifetime as similar as SMES. Nonetheless, they are expensive and have low energy density [37].

Among all the energy storage options available, the battery is widely used to store the PV power generated. Lead-acid battery ( $\mathrm{Pb}$-acid), sodium sulphur $(\mathrm{Na}-\mathrm{S})$ battery, nickel cadmium (Ni-Cd) battery and lithium-ion (Li-ion) battery are getting more attention recently to mitigate the voltage fluctuations. Their popularity is result of their wide availability, high energy density and low capital cost. However, the batteries have shorter lifetime than SMES and super capacitor. In addition, batteries need regular maintenance [9].

The characteristics for each of energy storage are summarized in Table 1 [37]. The SMES and super capacitor show the highest efficiency and have the longest lifetime. In addition, their charge time response is faster than the battery. However, their capital cost is higher than the batteries.

\subsection{Maximum Power Point Tracking (MPPT)}

MPPT is a method used to track the maximum solar irradiation point and improve the PV system efficiency, respectively. Maximum power point (MPP) trackers operate by continuously calculating the maximum power from the PV system. MPP tracker is a power electronic DC-DC converter with varying duty cycle and a pulse width generator [38]. 
To track the global maximum power point (GMPP), meta-heuristic methods such as Particle Swarm Optimization (PSO), Su Do Ku Puzzle based MPPT, Cuckoo Search, and Artificial Bee Colony (ABC) are developed.

The idea of using PSO method was developed in 1995 which is modeled after the social behavior of bird flocking [39]. This method is among the earliest meta-heuristic methods developed to overcome the PSC. Each particle in a swarm represents a candidate solution, the position in the optimum space and the velocity vector which determines the particle direction and speed value. The results showed that PSO has advantages of rapidity, flexibility and robustness [40-41].

Nevertheless, the MPP is easy to fall into the local maximum power point which generates the failure to track the GMPP [39]. On top of that, PSO involves an excessive amount of calculation. To overcome the limitation of PSO method, Su Do Ku puzzle pattern is proposed [42].

The theory of using Su Do Ku puzzle is adapted in the PV modules arrangement which distributes the shading effect over the array [42]. Various arrangement of shading patterns can be used to track the GMPP. A fixed configuration of panel is arranged based on the Su Do Ku pattern [43]. Same row of panel is applied to another different position in different rows. Therefore, the shade is dispersed almost evenly all over the array. An arrangement array of $5 \times 5,6 \times 4$, and $4 \times 6$ were proposed with a distance separation of 3 and number of cycle is 2 [44]. The results show that the arrangements generate more power that the normal total cross tied (TCT) arrangement. Nonetheless, the generated power may differ with the Su Do Ku pattern. The chosen arrangement may results lesser output power [44]. Moreover, this method is more appropriate for small size PV system.

Recently, Cuckoo search (CS) based MPPT algorithm has been proposed [45]. Cuckoo search proven for its robustness, has good convergence and demonstrate high efficiency [46]. This technique has been employed in a PV system and the result shows that this MPPT capable tracking the MPP within 100-250 ms under manipulated environmental conditions. Despite, the power loss during steady state is only 0.000008\% [45]. An improved Cuckoo Search (ICS) was proposed to overcome the random step length [46]. A large step length cost considerable time affecting the search accuracy. Meanwhile, a small step size will reduce the search speed. Thus, the low-power, high-power, normal and marked zone were introduced. The ICS took $0.88 \mathrm{~s}$ to track the MPP compared to the conventional CS which took $1.20 \mathrm{~s}$ to track the MPP. However, the tracking efficiency is slightly different which are $99.93 \%$ and 99.94\% for CS and ICS, respectively.

A study on the behavior of bees has been carried out in 2005 by Karaboga [47]. The bees behavior had introduced the Artificial Bee Colony (ABC) technique which adopting the foraging, learning, memorizing and information sharing characteristics. Findings from former researches states that the main advantages of the $\mathrm{ABC}$ are its simplicity, light computing complexity, high solutions accuracy, convergence independent of the initial conditions and its ability to adopt with local minima [48]. The number of successful convergence is $98.50 \%$ with accuracy of $99.22 \%$ under different shading patterns.

A fast MPPT computation process is important in order to ensure the maximum power extraction at complex partial shading. More recent MPPT methods at partial shading have been discussed and it is found that ICS and ABC techniques would give the best convergence and higher accuracy.

\subsection{PV Panel Cooling System}

Photovoltaic panels absorb a large part of the solar irradiation. Nonetheless, they converted only a small amount of this solar energy into electricity. The efficiency solar energy 
conversion into electric energy is intensely dependent on the type of the solar cell and the operating conditions.

As the PV panel absorbing the solar irradiation, the panel's surface can be heated up to $40^{\circ} \mathrm{C}$ above ambient temperature [49]. There are two ways that PV panels can be cooled which are by using active and passive cooling methods.

Active cooling always requires fans or pumps that utilize an external power input. Meanwhile, passive cooling requires no additional power to operate. Passive cooling method is relatively inefficient since the heat dissipation rate is slower than the active cooling method. Nevertheless, researchers prefer this cooling technique as it does not requires additional power to operate [19].

A review of cooling for PV panel has been made [18] and it is found that by implementing a cooling system for PV panel, the levelized cost of energy (LCE), greenhouse payback time (GPBT) and energy payback time (EPBT) can be reduced.

\section{Discussion}

The variability of PV installation system locations often leads to the non-uniform power generation because of surrounding obstacles. In order to mitigate the voltage quality issue, many methods had been employed. Former researchers had introduced the significant of dump load, SMES and energy storages.

The meta-heuristic MPPT methods also have been suggested to overcome the partial shading conditions impact. Technically, all of the methods are capable to reduce the voltage fluctuation. However, a detailed modelling using a PV system integrated with the mitigation technique installation is required to increase the system efficiency.

Many mathematical model investigation of PV system involve the use of computational technique to assure the robustness of the system. A computational platform such as MATLAB/Simulink, PSPICE, PSCAD/EMTDC, Multisim or a combination of them can be used to build and simulate a complete PV system circuit.

The corresponding experimental data will be used for proposed methods validation purpose. The experimental validation offers the expected accuracy levels quantification and demonstrates the reliability of the model in the practical conditions. Practically, the measured and simulated I-V properties of the absorbed solar power are compared. The amount of cost savings also will be computed.

\section{Conclusion}

An extensive literature review has been carried out on the challenges corresponding to the solar PV system. The minimization of non-uniform PV output power is the main point that needs to be focused in order to achieve a stability and continuously power to the load. The output power fluctuations can be reduced through the implementation of energy storage.

Likewise, the MPPT technique is proposed to be applied to overcome the partial shading conditions as well as enhancing the electricity generation. Thus, an advanced meta-heuristic MPPT technique is introduced to track the global maximum power point (GMPP).

On top of that, in order to enhance the high performance of PV panel and to ensure a longer PV panels' life, PV panel cooling method should be implemented to the system.

The authors would like to acknowledge the Ministry of Higher Education of Malaysia and the Universiti Malaysia Perlis, Perlis, Malaysia, for the financial support under FRGS (9003-00564).

\section{References}

1. A. Yilanci, I. Dincer, H. Ozturk, J. PECS, 35, 231-244 (2009). 
2. M. Hosenuzzaman, N. Rahim, J. Selvaraj, M. Hasanuzzaman, A. Malek, A. Nahar, J. RSER, 41, 284-297 (2015).

3. S. Mekhilef, A. Safari, W. Mustaffa, R. Saidur, R. Omar, M. Younis, J. RSER, 16, 386396 (2012).

4. K. Kow, Y. Wong, R. Rajkumar, R. Rajkumar, J. RSER, 56, 334-346 (2016).

5. Renewable \& Alternative Fuels - U.S. Energy Information Administration (EIA). Available: http://www.eia.gov/renewable/

6. J. Kim, J. Rivera, T. Meng, B. Laratte, S. Chen, J. Sol. Ener., 133, 249-258 (2016).

7. C. I. Ferreira and D. Kim, IJR, 39, 23-37 (2014).

8. 5 Top Solar Energy Stocks to Watch in 2016. Available: http://www.profitconfidential.com/stocks/5-top-solar-energy-stocks-to-watch-in-2016/

9. J. Wong, Y. Lim, J. Tang, E. Morris, J. RSER, 29, 535-545 (2014).

10. V. Quaschning, M. Muriel, VGB Congress Power Plants 2001, 1-8 (2001).

11. J. Hoppmann, J. Volland, T. Schmidt, V. Hoffmann, J. RSER, 39, 1101-1118 (2014).

12. S. Mirhassani, H. Ong, W. Chong, K. Leong, J. RSER, 49, 121-131 (2015).

13. High-Concentration Solar Photovoltaic Systems to Reach Greater Efficiencies, Boosting Appeal Against Conventional Solutions. Available: https://technology.ihs.com/493004/hihg-concentration-solar-photovoltaic-systems-toreach-greater-efficiencies-boosting-appeal-againts-conventional-solutions/

14. A. Abdullah, A. Ghoneim, A. Al-Hasan, J. RE, 26, 189-199 (2002).

15. IEA. Paris: International Energy Agency; (2010).

16. S. Saravanan, N. R. Babu, RSER, 57, 192-204 (2016).

17. K. Sundareswaran, P. Sankar, P. Nayak, S. Simon, S. Palani, IEEE Trans. Sustain. Ener., 6, 198-209 (2015).

18. H. Bahaidarah, A. Baloch P. Gandhidasan, RSER, 57, 1520-1544 (2016).

19. M. Hasanuzzaman, A. Malek, M. Islam, A. Pandey, N. Rahim, SE, 137, 25-45 (2016).

20. S. Shivashankar, S. Mekhilef, H. Mokhlis, M. Karimi, J. RSER, 59, 1170-1184 (2016).

21. N. Gautam, A. Kumar, 2015 2nd International Conference on Recent Advances in Engineering \& Computational Sciences (RAECS) (2015).

22. J. Matos, F. Silva, L. Ribeiro, IEEE Trans. Ind. Electron., 1 (2014).

23. A. Chidurala, T. Saha, N. Mithulananthan, 2013 Australasian Universities Power Engineering Conference (AUPEC) (2013).

24. R. Varma, B. Das, I. Axente, T. Vanderheide, 2011 IEEE Power and Energy Society General Meeting (2011).

25. R. Varma, E. Siavashi, B. Das, V. Sharma, 2012 IEEE Electrical Power and Energy Conference (2012).

26. D. Hung, N. Mithulananthan, R. Bansal, J. App. Ener., 113, 1162-1170 (2014).

27. S. Bae, S. Jeon, J. Park, IFAC-PapersOnLine, 48, 507-511 (2015).

28. Y. Xie, M. Zhang, G. Jiang, P. Geng, K. Yu, AMR, 1268-1272 (2014).

29. B. Kang, S. Kim, B. Sung, J. Park, IEEE Trans. Appl. Supercond., 22, 5701004-5701004 (2012).

30. A. Cultura, Z. Salameh, Proceedings of the International Conference on Computer Information Systems and Industrial Applications (2015).

31. J. Li, Y. Chen, Y. Liu, J. Ener. Pro., 16, 1693-1700 (2012).

32. B. Richards, G. Conibeer, Int. Journal of Hyd. Ener., 32, 2712-2718 (2007).

33. A. Werulkar, P. Kulkarni, J. RSER, 52, 1809-1822 (2015).

34. N. Das, H. Wongsodihardjo, S. Islam, J. RE, 74, 917-924 (2015).

35. Y. Li, G. Zhang, G. Lv, A. Zhang, R. Wang, J. Sol. Ener., 117, 167-179 (2015).

36. B. Huang, T. Hou, P. Hsu, T. Lin, Y. Chen, C. Chen, K. Li, K. Lee, RE, 88, 95-101 (2016).

37. A. Evans, V. Strezov, T. Evans, RSER, 16, 4141-4147 (2012). 
38. M. Obi, R. Bass, RSER, 58, 1082-1094 (2016).

39. L. Liu, X. Meng, C. Liu, RSER, 53, 1500-1507 (2016).

40. K. Ishaque, Z. Salam, IEEE Trans. Ind. Electron., 1 (2012).

41. K. Ishaque, Z. Salam, A. Shamsudin, M. Amjad, AE, 99, 414-422 (2012).

42. X. Yang, S. Deb, Int. J. Math. Model. and Num. Opt., 1, 330-343 (2010).

43. B. I. Rani, G. S. Ilango, C. Nagamani, IEEE TSE, 4, 594-601 (2013).

44. S. Malathy, R. Ramaprabha, IEEE PEDS, 341-346 (2015).

45. J. Ahmed, Z. Salam, AE, 119, 118-130 (2014).

46. J. Shi, F. Xue, Z. Qin, W. Zhang, L. Ling, T. Yang, J. P. Elect., 16, 287-296 (2016).

47. D.Karaboga, An idea based on honey bee swarm for numerical optimization, 6 (2005).

48. A. Benyoucef, A. Chouder, K. Kara, S. Silvestre, O. sahed, App. Soft Comp., 32, 38-48 (2015).

49. R. Stropnik, U. Stritih, RE, 97, 671-679 (2016). 